\title{
The time course of selected outcome measures in healthy women aged 65-74 years when varying exercise frequency and duration of an exercise walking programme
}

\author{
Neil A. Smart ${ }^{1 *}$, Richard H. Morton ${ }^{2}$, Surendran Sabapathy ${ }^{3}$, Clare Minahan $^{3}$, Gregory C. Gass ${ }^{4}$ \\ 1 School of Science and Technology, University of New England, Armidale, Australia 2 School of Sport and Exercise, Massey \\ University, New Zealand 3 School of Rehabilitation Sciences, Griffith University, Southport, Australia 4 Health Collaborative Research \\ Network, Central Queensland University, Rockhampton, Australia
}

\begin{abstract}
Background: We aimed to determine the time course of resting and exercise heart rates (HR); blood pressure (BP), changes in peak $\mathrm{VO}_{2}$, time to exhaustion (TTE) and gas exchange threshold (Tge) at a constant weekly exercise time [120 mins] with counterbalanced variations in exercise duration (60 vs. 30min) and weekly visits ( 2 vs. $4 . \mathrm{wk}^{-1}$ session per week).

Methods: Forty-six women aged 65-74 years were randomly assigned to 2 or 4 sessions. $\mathrm{wk}^{-1}$ ) for six weeks.

Results: Principal findings: (i) significant increase in Tge at six weeks, with no significant differences between exercise frequency or duration; (ii) no significant increase in peak values for $\mathrm{VO}_{2}, \mathrm{HR}$, minute ventilation and respiratory quotient after six weeks exercise training (iii) significant decreases in diastolic blood pressure (DBP) at rest and during exercise only in the 4 sessions. k $^{-1}$ group and (iv) significant decrease in systolic blood pressure (SBP) during exercise and post-exercise period for both groups and rapid time course changes in HR and BP.
\end{abstract}

Conclusions: Exercise elicited rapid reductions in HR and SBP during exercise and post-exercise recovery periods for both groups and there was no significant interaction between exercise duration and exercise frequency.

Citation: Smart NA, Morton RH, Sabapathy S, Minahan C, Gass GC (2014) The time course of selected outcome measures in healthy women aged 65-74 years when varying exercise frequency and duration of an exercise walking programme. Healthy Aging Research 3:4. doi:10.12715/har.2014.3.4

Received: May 28, 2014; Accepted: August 4, 2014; Published: August 14, 2014

Copyright: (C) 2014 Smart et al. This is an open access article distributed under the terms of the Creative Commons Attribution License, which permits unrestricted use, distribution, and reproduction in any medium, provided the original work is properly cited.

Competing interests: The authors have declared that no competing interests exist.

Sources of funding: The National Health \& Medical Research Council, Australia provided the funding for the study (No.376601).

*Email: nsmart2@une.edu.au

\section{Introduction}

In healthy women, aged 65-74 years, with no history of chronic disease, the optimum mix of exercise frequency and exercise duration on select outcome measures for a given exercise intensity, is unclear. Equally unclear is the time course for those select outcome measures and particularly when exercise frequency and duration are varied.
While an exercise dose can be prescribed in terms of frequency, duration, intensity and mode of exercise (continuous or intermittent) only recently have the exercise dose-response relationships become systematically examined and particularly for those persons with chronic diseases and metabolic syndrome [1-7]. 
Ishikawa-Takata et al. examined patients aged approximately 50 years with grade 1-2 hypertension before and after an 8 -week training program at $50 \%$ maximum/peak oxygen consumption $\left(\mathrm{VO}_{2} \mathrm{max} /\right.$ peak $)$ [3]. Although systolic and diastolic blood pressure (SBP and DBP) decreased significantly across all groups, the time course for the changes in SBP and DBP and heart rate (HR) were not reported [3]. Similarly, Church et al. [8] using a 6-month pre-post design with an exercise dose of 3-4 times per week, at $50 \% \mathrm{VO}_{2}$ peak with increasing levels of energy expenditure $(4,8,12 \mathrm{Kcal} / \mathrm{kg})$ and weekly exercise duration (72-192min), found significant increases in absolute and relative $\mathrm{VO}_{2}$ peak and maximum power. No time course changes were reported for these and other outcome measures. More recently, Earnest et al. [1], using a similar pre-post design reported "significant dose dependent increase in maximum cardio-respiratory capacity". Again there was no time course analysis for the reported significant cardiorespiratory changes or for the significant changes associated with metabolic syndrome. Knowing the time course of a primary outcome measure is important to objectively adjust the dose of the stimulus to maximise the response and provide comment on the expected time for improvement. If exercise is to be used as medicine, then the time course for primary outcome measures should be known if those primary outcome measures are to be maximised.

We therefore took the approach of standardizing the weekly exercise time (120 min.wk $\left.{ }^{-1}\right)$, exercise intensity (individual gas exchange threshold; Tge) and exercise mode (continuous walking) in a group of healthy women, aged 65-74 yr. We then examined the effect of varying exercise session duration (60 vs. 30 $\mathrm{min})$ and counter-balancing the exercise frequency (2 vs. 4 sessions. $\mathrm{wk}^{-1}$ ) resulting in a fixed total weekly exercise time (120mins) on the time course of resting, exercise and post-exercise recovery SBP and DBP, resting, exercise and post-exercise recovery heart rate, and pre-post changes in peak $\mathrm{VO}_{2}$, Tge, and time to exhaustion (TTE).

\section{Methods}

\section{Participants and Recruitment Strategies}

Forty-six women, aged 65-74 years participated. Participants were recruited from family medical clinics and through media advertisements. Potential participants were initially screened by telephone using a standardized set of questions to determine their suitability to enter a formal health screening. The formal health-screening included (i) explanation of all procedures, (ii) obtaining consent, (iii) anthropometry/spirometry, (iv) blood test, (v) medical examination and (vii) a clinical exercise test.

The cognitive capacity of each subject to give consent was determined using the Mini-Mental State Examination [9], participants were then asked for their written consent. Height and body mass were measured according to standard procedures [10]. Pulmonary function was assessed using a calibrated spirometry system (Medical Graphics Corporation, USA). A 12lead electrocardiogram (EKG) (Cardio Perfect, Welch Allyn Inc., USA) and blood pressure (BP) were measured at rest. Venous blood samples (fasting) were drawn $(0700-0830 \mathrm{~h})$ at an accredited pathology laboratory for determination of haemoglobin, hematocrit and plasma ferritin concentrations. Under direct medical supervision, a clinical exercise 'stress' test was conducted on a motorized treadmill as part of the formal health screening. Participants were then asked to visit their family physician with the healthscreening results and details of the experimental procedures for an opinion and recommendation as to their suitability to participate in the approved procedures. The inclusion criteria were: (i) nonsmoking, (ii) normal age-relative physical examination, (iii) no significant abnormalities in heart rhythm during the clinical exercise test, and (iv) no physician-determined musculoskeletal disability that would prevent completion of a walking program. The Human Research Ethics Committee at Bond University reviewed and approved all procedures in accordance with the Declaration of Helsinki.

\section{Experimental Design}

Participants were randomly assigned to either 2 or 4 sessions per week. Participants in both groups trained at their individual Tge and for the same weekly exercise duration (120 min. $\left.\mathrm{wk}^{-1}\right)$.

To determine the time course, we took weekly measurements for six weeks of SBP, DBP, BP, and $\mathrm{HR}$ at rest, during exercise and during the postexercise recovery. HR and $\mathrm{BP}$, at rest, were recorded during minute six of the 10-minute rest period. The exercise HR and BP were recorded during minute twenty-five of the last exercise session of each week. 
The post-exercise recovery, HR, SBP and DBP were recorded in the seated position towards the end of minute five of the post-exercise recovery period. Weekly attendance rates were recorded for each group. Percent body fat was estimated using methods described elsewhere [11]. Peak $\mathrm{VO}_{2}, \mathrm{HR}$, respiratory exchange ratio (RER), Tge and TTE were measured at weeks 0 and 6.

\section{Determination of Peak Oxygen Uptake and Gas- Exchange Threshold}

After receiving approval from their family physician to participate, all subjects were re-familiarized with the intended procedures. Each subject's preferred walking speed was determined at on a $1 \%$ grade. The preferred walking speed of each individual was used in all subsequent exercise tests and exercise training sessions. Each subject completed an incremental exercise test to volitional fatigue on a treadmill (Lode B.V., Netherlands) to determine their individual peak oxygen consumption $\left(\mathrm{VO}_{2}\right.$ peak), TTE and Tge. The incremental exercise test included a 4-min warm-up at $3.0 \mathrm{~km} \cdot \mathrm{h}^{-1}$ on a $1 \%$ grade, followed by an increase in speed each minute until the preferred walking speed for each individual was attained. Treadmill grade was then increased by $2 \%$ every minute until volitional fatigue or physician intervention precluded further exercise.

HR and rhythm was monitored continuously using a 12 lead EKG and brachial artery BP was measured by auscultation at 5-minute intervals throughout the exercise test. Carbon dioxide output $\left(\mathrm{VCO}_{2}\right),\left(\mathrm{VO}_{2}\right)$, and expired minute ventilation $\left(\mathrm{V}_{\mathbf{E}} @ \mathrm{BTPS}\right)$ were measured breath-by-breath and averaged every 30s using an open-circuit spirometry (Medical Graphics Corporation, St Paul, USA). The average of the two highest consecutive 30 -s values measured before volitional fatigue was used to determine peak gas exchange $\left(\mathrm{VO}_{2}, \mathrm{VCO}_{2}\right)$ values. The Tge was determined for each individual using the simplified Vslope method [12]. Each person who undertook an incremental exercise test did so in a body harness to mitigate any fear of falling/stumbling during the exercise test. The exercise test was conducted without the subject gripping or resting hands on the front rail of the treadmill and without strenuous encouragement.

\section{Exercise Training Program}

Participants walked on a motor driven treadmill for $4 \times 30$ minutes or $2 \times 60$ minutes per week, respectively. The exercise intensity for each individual was at their individual Tge. All participants walked for 120 $\mathrm{min} \cdot \mathrm{wk}^{-1}$ for six weeks. Each exercise training session included an additional a 3-min warm-up and a 3-min cool-down at $3 \mathrm{~km} \cdot \mathrm{h}^{-1}$ at $1 \%$ grade. Participants were fitted with a 5-lead EKG (Mortara Instrument Inc., USA) to monitor heart rate and rhythm throughout each exercise training session. Heart rate and blood pressure were recorded every 5 minutes throughout all exercise-training sessions.

During the first exercise training session at each individual's preferred walking speed, the treadmill gradient for each participant was determined to coincide with their $\mathrm{VO}_{2}$ at the Tge identified during their individual incremental exercise test. Participants were instructed to continue their normal daily activities.

\section{Data Theory, Analysis and Reduction}

In our results figures, the slope is the amount the response variable (BP, HR, etc.) changed (increases or decreases) per week, assuming a linear trend over the 6 week period. The SE is the standard error associated with week-by-week fitted trend (or expected) values. Analyses were conducted using Minitab Inc., State College, PA, USA. Analysis of covariance (ANCOVA) was applied in one detailed analysis to assess group and time trend effects and their interaction, using rest, exercise and post-exercise recovery data. Time was the linear covariate and (binary) indicator variables were used to estimate the differential effects of the groups (4 vs. 2 sessions.wk ${ }^{1}$ ), at rest, during exercise and during the post-exercise recovery both on the intercept and slope of the linear temporal effect. Statistical significance was considered $\mathrm{p}<0.05$.

\section{Results}

All participants were able to complete either 30 or 60 minutes of walking during their first visit and subsequent visits without impairment due to medical events. Anthropometric, haemoglobin, haematocrit and plasma ferritin concentrations, BP and lung function results at the start of the exercise-training 
program (wk 0) for both groups are presented in Table 1. There were no significant differences between the groups at week 0 for any variable in Table 1 . The number and percentage of participants receiving prescribed medications are shown in Table 2. There were a significantly higher percentage of participants in the twice-weekly group who received physicianprescribed medications for BP.

Table 1. Baseline (0 wk) anthropometric, haematological, blood pressure and lung function for both exercise groups (Mean $\pm \mathrm{SD}$ )

\begin{tabular}{|c|c|c|c|}
\hline & $\begin{array}{c}\text { Group 1 } \\
\left(4 \text { sessions.wk }^{-1}\right) \\
(n=23)\end{array}$ & $\begin{array}{c}\text { Group 2 } \\
\left(2 \text { sessions.wk- }{ }^{-1}\right) \\
(\mathbf{n}=23)\end{array}$ & p-value \\
\hline Age (yr.) & $68.0 \pm 3.3$ & $68.0 \pm 2.9$ & 0.92 \\
\hline Body Mass (kg) & $71.7 \pm 13.9$ & $67.7 \pm 9.8$ & 0.26 \\
\hline Body Mass Index (kg.m $\left.{ }^{-2}\right)$ & $28.3 \pm 4.7$ & $26.7 \pm 4$ & 0.21 \\
\hline Body Fat (\%) & $31 \pm 3$ & $31 \pm 5$ & 0.54 \\
\hline Systolic BP (mmHg) & $130 \pm 11$ & $125 \pm 10$ & 0.08 \\
\hline Diastolic BP (mmHg) & $78 \pm 6$ & $78 \pm 8$ & 0.89 \\
\hline Pulse Pressure (mmHg) & $53 \pm 9.5$ & $47 \pm 7.8$ & 0.01 \\
\hline Haemoglobin (g.L $\left.{ }^{-1}\right)$ & $132 \pm 10$ & $130 \pm 9$ & 0.44 \\
\hline Haematocrit & $0.41 \pm 0.03$ & $0.40 \pm 0.02$ & 0.17 \\
\hline Ferritin $\left(\mu \mathrm{g} . \mathrm{L}^{-1}\right)$ & $134 \pm 83$ & $113 \pm 65$ & 0.42 \\
\hline Forced Vital Capacity (L) & $2.7 \pm 0.4$ & $2.8 \pm 0.4$ & 0.82 \\
\hline Forced Expiratory Volume (1s) (L) & $2.2 \pm 0.3$ & $2.3 \pm 0.4$ & 0.65 \\
\hline $\mathrm{FEV}_{\mathrm{l}} / \mathrm{FVC}(\%)$ & $80 \pm 3$ & $80 \pm 5$ & 0.16 \\
\hline
\end{tabular}

Table 2. Number and percentage of participants receiving prescribed medications

\begin{tabular}{lccc}
\hline & \multicolumn{3}{c}{ Medications [N, (\%)] } \\
\cline { 2 - 4 } & $\begin{array}{c}\text { Group 1 } \\
\left.\text { (4 sessions.wk }{ }^{-1}\right)\end{array}$ & $\begin{array}{c}\text { Group 2 } \\
(2 \text { sessions.wk }\end{array}$ & p-value \\
\hline Cholesterol & $5(22)$ & $7(30)$ & 0.73 \\
Blood pressure & $2(9)$ & $9(39)$ & 0.04 \\
Osteoporosis & $5(22)$ & $4(17)$ & 0.88 \\
Arthritis & $1(4)$ & $4(17)$ & 0.34 \\
Depression & $1(4)$ & $0(0)$ & 0.31 \\
Thyroid & $3(12)$ & $0(0)$ & 0.23 \\
Other & $9(39)$ & $11(48)$ & 0.76 \\
\hline
\end{tabular}

\section{Time Course}

\section{Heart rate}

The week-by-week means in HR for (4 sessions.wk $\left.{ }^{-1}\right)$ and $\left(2\right.$ sessions.wk $\left.{ }^{-1}\right)$ at rest, during exercise and during the post-exercise recovery period are presented in Fig. 1 A, B, and C, respectively, with the best fit linear trends. There were no significant group or time trends for HR at rest ( $\mathrm{p}>0.4$ and $\mathrm{p}>0.3$, respectively).

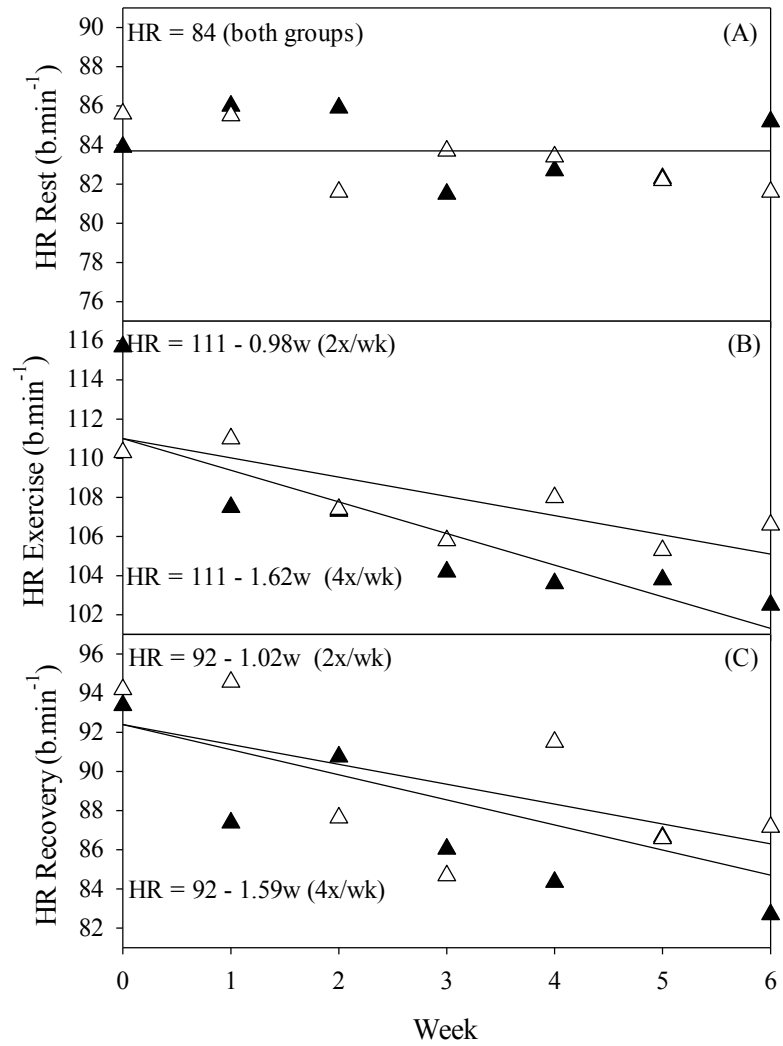

Figure 1. Weekly heart rate (HR) measurements

$\mathrm{HR}$ at rest (A) during exercise (B) and during post exercise recovery (C) for Group 1 ( $\boldsymbol{\Delta} 4$ sessions.wk $\left.{ }^{-1}\right)$ and Group 2 ( $\Delta 2$ sessions. $\mathrm{wk}^{-1}$ ) for each week of the exercise training program

The weekly exercise and post-exercise recovery HRs for both groups are presented in Fig. 1B and Fig. 1C respectively. The time trend for exercise HR for 4weekly sessions had slope $=-0.98$ b. $\mathrm{min}^{-1}, \mathrm{SE}=0.33$, $\mathrm{p}<0.05$ ) and for 2-weekly sessions, slope $=-1.62$ b. $\min ^{-1}, \mathrm{SE}=0.33 \mathrm{p}<0.01$. The post-exercise recovery HR for 4-weekly sessions was slope $=-1.02 \mathrm{~b} \cdot \mathrm{min}^{-1}$, $\mathrm{SE}=0.32 \mathrm{p}<0.05)$ and for 2-weekly sessions slope $=$ 1.59 b. $\mathrm{min}^{-1}, \mathrm{SE}=0.32 \mathrm{P}<0.01$. The downward slopes during exercise and post-exercise were not significantly different within either group $(p>0.3$ for both during and post-exercise). The adjusted $\mathrm{R}^{2}$ for the fitted ANCOVA model was 0.96 .

\section{Systolic Blood Pressure (SBP)}

The week-by-week means in SBP for each group at rest, during exercise and during the post-exercise recovery period are presented in Fig. 2A, B, and C, respectively, with the best fit linear trends. 


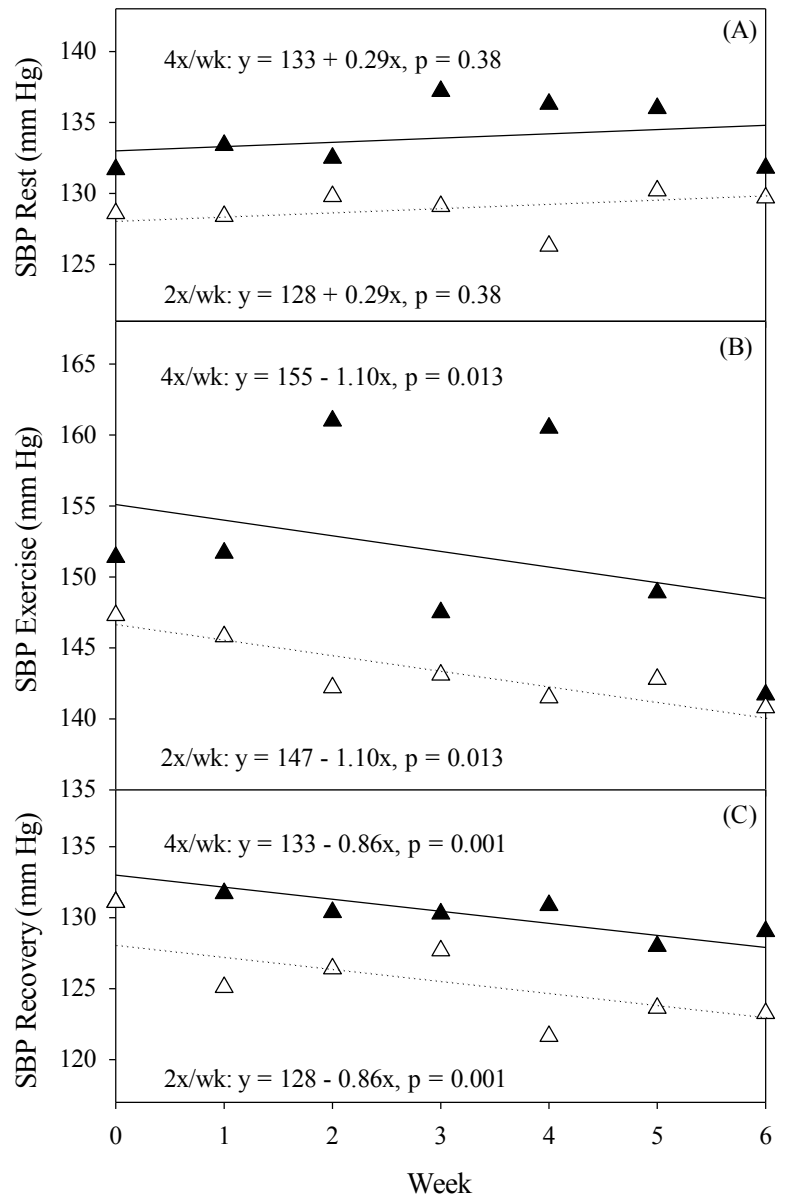

Figure 2. Weekly systolic blood pressure (SBP) measurements

SBP at rest (A), during exercise (B) and during post exercise recovery $(C)$ for Group $1\left(\boldsymbol{\Delta} 4\right.$ sessions.wk $\left.{ }^{-1}\right)$ and Group $2(\Delta 2$ sessions. $\left.\mathrm{wk}^{-1}\right)$ for each week of the exercise training programme.

During the initial week (week 0), SBP was significantly higher at rest in the 4-weekly sessions group than in 2-weekly sessions group, $(\mathrm{p}=0.001)$. For both groups, the week-by-week SBP at rest remained essentially unchanged ( $\mathrm{p}=0.38$ ) (Fig. 2A).

Similarly, during exercise, SBP during the initial (week 0) was significantly higher in the 4-weekly sessions group than in 2-weekly sessions group $(p=0.001)$. The week-by-week SBP for both groups trended downwards significantly $(\mathrm{p}=0.013)$ and with common slopes (Fig. 2B).

Both groups also showed a significant $(\mathrm{p}=0.001)$ downward trend in SBP during the post-exercise recovery periods and had common slopes.

\section{Diastolic blood pressure (DBP)}

The week-by-week means in DBP for each group at rest, during exercise and during the post-exercise recovery period are presented in Fig. 3A, B, and C, respectively, together with the best fit linear trends.

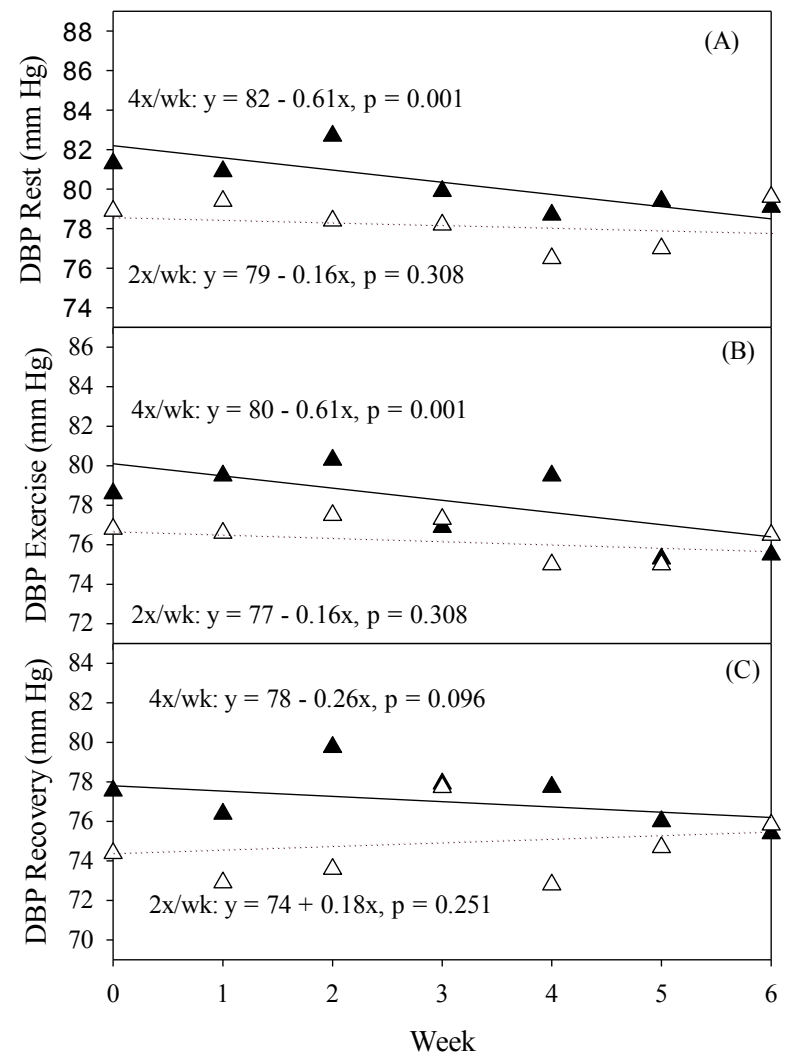

Figure 3. Weekly diastolic blood pressure (DBP) measurements

DBP at rest (A), during exercise (B) and during post exercise recovery $(\mathrm{C})$ for Group 1 ( $\boldsymbol{\Delta} 4$ sessions.wk ${ }^{-1}$ ) and Group 2 ( $\Delta 2$ sessions. $\left.\mathrm{wk}^{-1}\right)$ for each week of the exercise training programme.

Resting DBP during the initial (wk 0) was significantly higher for the 4-weekly sessions group than in the two weekly sessions group $(\mathrm{p}<0.001)$. DBP in both groups trended downwards, but was significant only in the 4 sessions. $\mathrm{wk}^{-1}$ group $(\mathrm{p}=0.001)$. The difference in slope between 4-weekly sessions and two weekly sessions groups was significant $(\mathrm{p}=0.035)$ (Fig. $3 \mathrm{~A})$.

During exercise, the initial DBP was significantly lower than at rest and by a similar amount in both groups $(-2 \mathrm{mmHg}, \mathrm{p}<0.001)$. Week-by-week DBP in 
both groups during exercise trended downwards, but again was significant only in the 4-weekly sessions group, $(p=0.001)$. The difference in slope between 4weekly sessions and two-weekly sessions groups was also significant ( $\mathrm{p}=0.035)$ (Fig. 3B). During the postexercise recovery periods, the initial DBP was also significantly lower than at rest and by an equal amount $(-4 \mathrm{mmHg})$ in both groups $(\mathrm{p}<0.001)$ (Fig. $3 \mathrm{C})$.

\section{Pulse Pressure}

Pulse pressure $(\mathrm{mmHg})$ was $53 \pm 9.5 \mathrm{mmHg}$ in the twice weekly group and $47 \pm 7.8 \mathrm{mmHg}$ in the 4 times weekly group ( $\mathrm{p}=0.01)$, after 6 weeks exercise pulse pressure was unchanged $(50.6 \pm 1.2 \mathrm{mmHg}, \mathrm{p}=\mathrm{NS})$ in the twice weekly group but had increased to $6.8 \pm 1.5 \mathrm{mmHg}$ in the four times weekly group $(\mathrm{p}<0.01)$.

\section{Peak VO2 and Treadmill Time to Exhaustion}

The incremental exercise test results for 4-weekly sessions and two weekly sessions, before $(0 \mathrm{wk})$ and after $(6 \mathrm{wk})$ the exercise training program are presented in Table 3. At the end of 6 weeks, participants in 4 weekly sessions and 2 weekly sessions were training at approximately $74 \%$ and $75 \%$ $\mathrm{VO}_{2}$ peaks, respectively. There was a significant increase in $\mathrm{VO}_{2} @$ Tge $(\mathrm{p}=0.006)$ and TTE $(\mathrm{p}=0.003)$ for the 4-weekly sessions and 2-weekly sessions after six weeks and no significant difference between the two groups. There were no significant differences in peak $\mathrm{VO}_{2}\left(\mathrm{~mL} \cdot \mathrm{kg}^{-1} \cdot \mathrm{min}^{-1}\right), \mathrm{HR}$, and RER for either group.

Table 3. Clinical exercise test results before (week 0 ) and after six weeks (week 6) of an exercise-training program (Mean \pm SD)

\begin{tabular}{|c|c|c|c|c|c|c|}
\hline & \multicolumn{3}{|c|}{$\begin{array}{c}\text { Group 1 } \\
4 \text { sessions.wk }^{-1}(n=23)\end{array}$} & \multicolumn{3}{|c|}{$\begin{array}{c}\text { Group 2 } \\
\text { 2 sessions.wk }{ }^{-1}(n=23)\end{array}$} \\
\hline & Week 0 & Week 6 & p-value & Week 0 & Week 6 & p-value \\
\hline 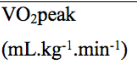 & $20.7 \pm 3.4$ & $21.5 \pm 4.1$ & 0.30 & $22.5 \pm 4.0$ & $23.6 \pm 3.3$ & 0.45 \\
\hline $\begin{array}{l}\text { HRmax } \\
\text { (beats.min }{ }^{-1} \text { ) }\end{array}$ & $150 \pm 14$ & $149 \pm 13$ & 0.52 & $157 \pm 11$ & $156 \pm 10$ & 0.87 \\
\hline RER & $1.12 \pm 0.10$ & $1.10 \pm 0.08$ & 0.19 & $1.14 \pm 0.08$ & $1.13 \pm 0.08$ & 0.72 \\
\hline $\begin{array}{l}\mathrm{VO}_{2} @ \text { Tge } \\
\left(\mathrm{mL} \cdot \mathrm{kg}^{-1} \cdot \mathrm{min}^{-1}\right)\end{array}$ & $14.8 \pm 3.2$ & $15.9 \pm 2.6$ & 0.002 & $15.5 \pm 1.9$ & $17 \pm 2.5$ & 0.006 \\
\hline $\begin{array}{l}\text { TTE } \\
(\min )\end{array}$ & $14.6 \pm 2.5$ & $15.4 \pm 2.7$ & 0.008 & $15.5 \pm 2.2$ & $16.6 \pm 1.8$ & 0.003 \\
\hline
\end{tabular}

HR max: Heart rate maximum; RER: Respiratory exchange ratio; Tge: Gas exchange threshold; TTE: Time to exhaustion

\section{Attendance}

The overall attendance during the 6-wk exercise training program for 4-weekly sessions and twoweekly sessions was $91 \pm 4 \%$ and $92 \pm 3 \%$ respectively. There were no significant differences in overall attendance between the 4-weekly sessions group and two-weekly sessions group or between each week of the exercise-training program.

\section{Discussion}

The present study is the first to report a time course for SBP, DBP and HR at rest, during exercise and during post-exercise recovery period in healthy women aged 65-74 yr. Our principal findings were: (i) significant decreases in HR only during the exercise and post exercise recovery periods for both groups and with similar time courses, (ii) significant decrease in SBP during exercise and post-exercise recovery periods for both groups and with similar time courses, (iii) significant decreases in DBP at rest and during exercise only in 4 sessions. $\mathrm{wk}^{-1}$ with a time course significantly different from 2 sessions. $\mathrm{wk}^{-1}$, (iv) rapid time course responses for HR and SBP during exercise and post-exercise recovery periods and for both groups (v) Increase in pulse pressure only in the 4-weekly sessions group (vi) significant increase in Tge and TTE after six weeks, for both groups; (vii) no significant increase in peak values for $\mathrm{VO}_{2}, \mathrm{HR}$, minute ventilation and RER for either group.

While it has been previously reported that there is no change in resting HR after 6 weeks of training [13], this is contradictory to the findings of others $[14,15]$. During the exercise and post-exercise recovery periods there was a significant time trend decrease in HR for both groups, which has also been reported by others $[14,15]$. Improved baroreflex sensitivity may explain resting bradycardia [16] and could also explain exercise and post-exercise recovery bradycardia. In our work, exercise HR decreased within 2-3 weeks of a moderate intensity [@Tge] walking exercise program, suggesting periodic increases in intensity may be required to maintain the same relative effort.

Participants in both groups were defined as normotensive. Higher SBP in the 4-weekly sessions group may reflect the significantly higher percentage of participants taking blood pressure medication (39 vs. 9\%; Table 2]. Absence of a significant decrease in 
SBP at rest during the 6 week exercise training period is consistent with results of some studies [17-19] but is in contrast to others [20-23]. Previous work has reported that the greatest blood pressure reductions occur in the first 3 months of exercise training [23]. Because our participants were normotensive/prehypertensive, a significant reduction in resting SBP is less likely [3,24,25].

While the 4 times weekly group showed a significant week-by-week downward trend in resting DBP, others have reported declines in DBP at rest [7 $\mathrm{mmHg}$ ] [22] with inverse linear relationships between weeks 1,3 and 5 of training and the decrease in resting DBP [4]. Like SBP, DBP appears to decrease the most during the first 3 months of training [23]. Murray et al. [15] also identified a decrease in resting DBP as early as three exercise sessions [week 1] and continued to decline for the next three weeks. While it is difficult to determine how much of the decline in DBP at rest that was observed in the 4-weekly sessions group was due to their higher initial DBP, a decline in DBP during exercise [22] and high intensity exercise $(12 \mathrm{kcal} / \mathrm{kg})$ [18] has been previous reported. For both groups, there was a significant downward trend in exercise SBP for each week of the 6-weeks of training.

The mechanisms reported to explain the decrease in SBP $[20,26]$ typically relate to SBP at rest and not during exercise. Recent work has suggested exercise modality may influence the magnitude of blood pressure change [27]. The progressive decline in SBP during exercise in the present study may involve those same mechanisms [20] and also include positive changes in vascular conductance [15], increased parasympathetic nervous system activity [28], arterial stiffness [25] and $\mathrm{H} 1$ and $\mathrm{H} 2$ receptors [29], although ambulatory monitoring may be a more reliable measure of changes in SBP [30].

For both groups the SBP during the exercise recovery period decreased significantly each week over the sixweek training program, others have reported similar results [25] and with moderate intensity exercise [31,21]. Only the 4 times weekly group had a significant decrease in post-exercise DBP, in agreement with others $[18,20]$ and may reflect higher initial DBP.

After six weeks of exercise training there was a significant increase in the $\mathrm{VO}_{2} @$ Tge and TTE for both groups and no significant differences between groups. The observed increase in $\mathrm{VO}_{2} @$ Tge is in agreement with the results of others [14,33] on women aged $69 \pm 7 \mathrm{yr}$. and $53.5 \pm 4.6 \mathrm{yr}$., respectively. Murias et al. (2010) reported a higher gain in $\mathrm{VO}_{2}$ @ Tge (14\%) after six weeks of cycling exercise in men [14]. Whether exercise mode (walking vs. cycling) or gender affected the magnitude of change in $\mathrm{VO}_{2} @$, Tge is unknown. Increased TTE after 6 weeks training is consistent with results of others $[14,34]$, but occurred without significant increases in peak $\mathrm{VO}_{2}$ and $\mathrm{HR}$.

In the present study, there was no significant increase in the pre-post exercise peak $\mathrm{VO}_{2}$ confirming work of others [13] but differing from some studies [14]. While there may be concern about whether each individual in the present study reached their "maximum $\mathrm{VO}_{2}$ " during the pre/post-tests, supporting evidence (peak HR, RER, TTE) would suggest that the highest $\mathrm{VO}_{2}$ was attained. Attendance for the 4$(91 \pm 4 \%)$ and 2-weekly sessions groups $(92 \pm 3 \%)$ is similar to previous work [35] and may reflect the homogenous age of our participants [36] and their proximity to the exercise site [37]. Weekly frequency of the exercise program ( 2 vs. 4 sessions. $w^{-1}$ ) may not be a major consideration when prescribing exercise for women aged 65-74 yr. The insignificant changes in peak $\mathrm{VO}_{2}$ and $\mathrm{HR}$ after 6 weeks of exercise training despite significant increases in Tge@ $\mathrm{VO}_{2}$ and TEE, may be reflective of the exercise training intensity employed [38]. There was no significant increase in pre-post peak HR, which has been reported previously [1].

\section{Limitations}

We did not receive ethical approval to conduct weekly incremental exercise tests to exhaustion and therefore cannot speculate as to the time course for $\mathrm{VO}_{2} @ \mathrm{Tge}$ and TTE.

We make the following recommendations for exercise prescriptions in older women; (i) two hours of moderate intensity walking may reduce resting HR and $\mathrm{BP}$, and this activity may be accumulated in two or four weekly sessions, without affecting magnitude of adaptation; (ii) moderate intensity walking in excess of two hours may be required to improve cardio-respiratory fitness, and (iii) optimal improvements in cardio-respiratory fitness, HR and BP may be achieved by reviewing exercise intensity every 2-3 weeks to ensure relative intensity has not fallen due to adaptation. 


\section{Conclusions}

In summary, there were rapid and significant decreases in HR and SBP during the exercise and post-exercise recovery period for both groups. Significant decreases in DBP occurred at rest and during exercise only in the 4 sessions. $\mathrm{wk}^{-1}$ group. Significant increases in Tge and TTE were found for both groups. There were no significant increases in peak values for $\mathrm{VO}_{2}$, RER and HR for either group. Significant and rapid changes occurred in other dependent variables, independent of $\mathrm{VO}_{2}$ peak and exercise frequency and duration.

\section{Acknowledgements}

The authors would like to acknowledge the participants of the study and Professor Norman Morris and Associate Prof. Luke Haseler.

\section{References}

1. Earnest CP, Johannsen NM, Swift DL, Lavie CJ, Blair $\mathrm{SN}$, Church TS. Dose effect of cardiorespiratory exercise on metabolic syndrome in postmenopausal women. Am J Cardiol. 2013;111:1805-11.

2. Houmard JA, Tanner CJ, Slentz CA, Duscha BD, McCartney JS, Kraus WE. Effect of the volume and intensity of exercise training on insulin sensitivity. J Appl Physiol. 2004;96:101-6.

3. Ishikawa-Takata $\mathrm{K}$, Ohta $\mathrm{T}$, Tanaka $\mathrm{H}$. How much exercise is required to reduce blood pressure in essential hypertensives: a dose-response study. Am J Hypertens. 2003;16:629-33.

4. Liu S, Goodman J, Nolan R, Lacombe S, Thomas SG. Blood pressure responses to acute and chronic exercise are related in prehypertension. Med Sci Sports Exerc. 2012;44:1644-52.

5. Morss GM, Jordan AN, Skinner JS, Dunn AL, Church TS, Earnest CP, et al. Dose Response to Exercise in Women aged 45-75 yr (DREW): design and rationale. Med Sci Sports Exerc. 2004;36:336-44.

6. Powell KE, Paluch AE, Blair SN. Physical activity for health: What kind? How much? How intense? On top of what? Annu Rev Public Health. 2011;32:349-65.

7. Vanhees L, De Sutter J, GeladaS N, Doyle F, Prescott E, Cornelissen $\mathrm{V}$, et al. Importance of characteristics and modalities of physical activity and exercise in defining the benefits to cardiovascular health within the general population: recommendations from the EACPR (Part I). Eur J Prev Cardiol. 2012;19:670-86.

8. Church TS, Earnest CP, Skinner JS, Blair SN. Effects of different doses of physical activity on cardiorespiratory fitness among sedentary, overweight or obese postmenopausal women with elevated blood pressure: a randomized controlled trial. JAMA. 2007;297(:2081-91.

9. Folstein MF, Folstein SE, McHugh PR. "Mini-mental state". A practical method for grading the cognitive state of patients for the clinician. J Psychiatr Res. 1975; 12:189-98.

10. Freitag E, Edgecombe G, Baldwin I, Cottier B, Heland M. Determination of body weight and height measurement for critically ill patients admitted to the intensive care unit: A quality improvement project. Crit Care. Nov 2010;23:197-207.

11. Jensky-Squires NE, Dieli-Conwright CM, Rossuello A, Erceg DN, McCauley S, Schroeder ET. Validity and reliability of body composition analysers in children and adults. The British journal of nutrition. 2008;100:85965.

12. Schneider DA, Phillips SE, Stoffolano S. The simplified V-slope method of detecting the gas exchange threshold. Med Sci Sports Exerc. 1993;25:1180-4.

13. Pullin CH BM, Bailey D, Ashton M, Davies B, Williams $\mathrm{S}$, Goodfellow J, et al. Time Course of Changes in Endothelial Function Following Exercise in Habitually Sedentary Men. J Exercise Physiol. 2004;7:14-22.

14. Murias JM, Kowalchuk JM, Paterson DH. Time course and mechanisms of adaptations in cardiorespiratory fitness with endurance training in older and young men. J Appl Physiol. 2010;108:621-7.

15. Murray A, Delaney T, Bell C. Rapid onset and offset of circulatory adaptations to exercise training in men. $\mathrm{J}$ Hum Hypertens. 2006;20:193-200.

16. Collier SR, Kanaley JA, Carhart R Jr, Frechette V, Tobin MM, Bennett $\mathrm{N}$, et al. Cardiac autonomic function and baroreflex changes following 4 weeks of resistance versus aerobic training in individuals with pre-hypertension. Acta Physiol (Oxf). 2009;195:339-48.

17. Stewart KJ, Bacher AC, Turner KL, Fleg JL, Hees PS, Shapiro EP, et al. Effect of exercise on blood pressure in older persons: a randomized controlled trial. Arch Intern Med. 2005;165:756-62.

18. Swift DL, Earnest CP, Katzmarzyk PT, Rankinen T, Blair SN, Church TS. The effect of different doses of aerobic exercise training on exercise blood pressure in overweight and obese postmenopausal women. Menopause. 2012;19:503-9.

19. Zarins ZA, Wallis GA, Faghihnia N, Johnson ML, Fattor JA, Horning MA, et al. Effects of endurance training on cardiorespiratory fitness and substrate partitioning in postmenopausal women. Metabolism. 2009;58:1338-46.

20. Cornelissen VA, Goetschalckx K, Verheyden B, Aubert AE, Arnout J, Persu A, et al. Effect of endurance training on blood pressure regulation, biomarkers and the heart in subjects at a higher age. Scand J Med Sci Sports. 2011;21:526-34.

21. Cornelissen VA, Verheyden B, Aubert AE, Fagard RH. Effects of aerobic training intensity on resting, exercise and post-exercise blood pressure, heart rate and heartrate variability. J Hum Hypertens. 2010;24:175-82.

22. Viecili PR, Bündchen DC, Richter CM, Dipp T, Lamberti DB, Pereira AM, et al. Dose-response curve to 
exercise in hypertensive individuals: analysis of the number of sessions to the hypotensive effect. Arq Bras Cardiol. 2009;92:361-367, 378-384, 393-69.

23. Cornelissen VA, Smart NA. Exercise training for blood pressure: a systematic review and meta-analysis. J Am Heart Assoc. 2013;2:e004473.

24. Cornelissen VA, Fagard RH. Effect of resistance training on resting blood pressure: a meta-analysis of randomized controlled trials. J Hypertens. 2005;23:2519.

25. Tabara Y, Yuasa T, Oshiumi A, Kobayashi T, Miyawaki $\mathrm{Y}$, Miki T, et al. Effect of acute and long-term aerobic exercise on arterial stiffness in the elderly. Hypertens Res. 2007;30:895-902.

26. Gibbs BB, Brancati FL, Chen H, Coday M, Jakicic JM, Lewis CE, et al. Effect of improved fitness beyond weight loss on cardiovascular risk factors in individuals with type 2 diabetes in the Look AHEAD study. Eur $\mathbf{J}$ Prev Cardiol. 2014;21:608-17.

27. Carlson DJ DG, Hess N, Millar P, Smart NA. Isometric exercise training for blood pressure management: A systematic review and meta-analysis. Mayo Clinic Proceedings. 2014;89:327-34.

28. Piotrowicz E, Baranowski R, Piotrowska M, Zielinski T, Piotrowicz R. Variable effects of physical training of heart rate variability, heart rate recovery, and heart rate turbulence in chronic heart failure. Pacing Clin Electrophysiol. 2009;32:S113-5.

29. McCord JL, Beasley JM, Halliwill JR. H2-receptormediated vasodilation contributes to postexercise hypotension. J Appl Physiol. 2006;100:67-75.

30. Cornelissen VA, Buys R, Smart NA. Endurance exercise beneficially affects ambulatory blood pressure: a systematic review and meta-analysis. J Hypertens. 2013;31:639-48.

31. Kenney MJ, Seals DR. Postexercise hypotension. Key features, mechanisms, and clinical significance. Hypertension. 1993;22:653-64.

32. Halliwill JR, Buck TM, Lacewell AN, Romero SA. Postexercise hypotension and sustained postexercise vasodilatation: what happens after we exercise? Exp Physiol. 2013;98:7-18.

33. Robbins JL, Duscha BD, Bensimhon DR, Wasserman K, Hansen JE, Houmard JA, et al. A sex-specific relationship between capillary density and anaerobic threshold. J Appl Physiol. 2009;106:1181-6.

34. Ciolac EG. High-intensity interval training and hypertension: maximizing the benefits of exercise? Am J Cardiovasc Dis. 2012;2:102-10.

35. Dobrosielski DA, Gibbs BB, Ouyang P, Bonekamp S, Clark JM, Wang NY, et al. Effect of exercise on blood pressure in type 2 diabetes: a randomized controlled trial. Journal of general internal medicine. 2012;27:1453-9.

36. Dunlop WL, Beauchamp MR. The relationship between intra-group age similarity and exercise adherence. Am J Prev Med. 2012;42:53-5.

37. Cabral-de-Oliveira AC, Ramos PS, Araujo CG. Distance from home to exercise site did not influence the adherence of 796 participants. Arq Bras Cardiol. 2012;98:553-8.

38. Ismail $H$, McFarlane JR, Nojoumian AH, Dieberg G, Smart NA. Clinical outcomes and cardiovascular responses to different exercise training intensities in patients with heart failure: a systematic review and meta-analysis. JACC. Heart failure. 2013;1:514-22. 